\title{
Improving and Balancing Software Qualities
}

\author{
Barry Boehm \\ USC \\ 941 Bloom Walk, SAL 328 \\ Los Angeles, CA 90089, USA \\ 1-213-740-8163 \\ boehm@usc.edu
}

\begin{abstract}
This Technical Briefing describes the nature of Software Qualities (SQs), ilities, or non-functional requirements (reliability, usability, affordability, etc.), and discusses the importance of understanding their nature and interrelationships, and of bringing them into balance in the practice of software engineering. The relevance and timeliness of this topic reflects the current and future trends toward more software-intensive systems, with greater complexity, autonomy, speed of change, and need for interoperability within systems of systems, given the frequent system shortfalls and overruns that occur when their SQ balance is not achieved. It discusses the weaknesses of current SQ standards and guidance, and summarizes research toward strengthening current SQ definitions and relationships. This includes a set of initial SQ ontology elements and relationships, examples of their application to some key SQs, an identification of further research and development needed to make the ontology fully useful and evolvable, and the nature of an international collaborative effort to help improve current practices via a Qualipedia for accessing the evolving body of knowledge for improving SQ engineering.
\end{abstract}

\section{CCS Concepts}

- Software and its engineering $\rightarrow$ Software organization and properties $\rightarrow$ Extra-functional properties

\section{Keywords}

Software qualities ontology; Means-ends relationships; Referent; Stakeholder value propositions; Referents; States; Processes; Relationships; Quality Attributes; Ilities

\section{INTRODUCTION}

The nature of the SQs is best understood with respect to their synonym of extra-functional properties as above. Functional requirements specify the functions that a software-intensive system shall perform, or basically what it should do. Their effect on software and system cost is basically additive; adding a function adds the cost to develop it, plus another fraction for its contribution to software-system integration and test. An extra-functional requirement specifies how well the system and software should perform their functions.

Permission to make digital or hard copies of all or part of this work for personal or classroom use is granted without fee provided that copies are not made or distributed for profit or commercial advantage and that copies bear this notice and the full citation on the first page. Copyrights for third-party components of this work must be honored. For all other uses, contact the Owner/Author.

Copyright is held by the owner/author(s).

ICSE '16 Companion, May 14-22, 2016, Austin, TX, USA

ACM 978-1-4503-4205-6/16/05.

http://dx.doi.org/10.1145/2889160.2891049
Unlike functional requirements, its effect on system cost is systemwide and multiplicative. In one example, changing the response time for a complex system with 2000 pages of functional requirements from 1 second to 4 seconds reduced the cost from $\$ 100$ million to $\$ 30$ million, in this case by avoiding the need for an expensive custom solution, and by showing that a 4 -second response time was acceptable for $90 \%$ of the transactions and achievable via commercial technology. However, functional requirements are much more emphasized in system acquisitions, via such practices as initial system functional review milestones, function-oriented system definition diagrams, functional work breakdown structures and associated earned value milestones, and functional traceability matrices. The SQ requirements trace to the entire software architecture and product, or at least to all of a set of complex stimulus-response threads, not just to a part of the design.

\section{MOTIVATION AND CONTEXT}

The Technical Briefing will begin by summarizing the motivation for the topic and explain the nature and importance of the SQs, using the project described above as an example of the increasing need to improve and balance the SQs. For example, current and future trends are toward more software-intensive systems, with greater complexity, autonomy, speed of change, and need for interoperability within systems of systems. Examples are Internets of Things, massive-data analytics, self-driving cars, dynamic global supply chains, and software-driven human prosthetics, with associated needs for simultaneous achievement of higher levels of safety, security, scalability, adaptability, multi-cultural usability, speed of development and evolution, and affordability.

It will continue by summarizing some of the major weaknesses of current SQ practices. The leading current standard in the area, ISO/IEC 25010 [7] is particularly weak. For example, it defines Reliability as the "degree to which a system, product, or component performs specified functions under specified conditions for a specified period of time." As a standard, this is supposed to hold for any definition of "specified functions" and "specified conditions." However, for agile methods, "specified functions and conditions" are often sunny-day stories or use cases, and a system will then be judged to be ISO/IEC-reliable if it satisfies only the specified sunny-day conditions, but fails on the rainy-day conditions. Further, the standard only focuses on performing functions and not on satisfying SQ levels.

Another weakness is the diversity of SQ definitions. For example, the definitions of the SQ Resilience in Wikipedia differ between and within the domains of Ecology, Energy Development, Engineering and Construction, Network, Organizational, Psychological, and Soil. Within the Ecology and Society domain, an additional set of definitions includes Original-ecological, Extended-ecological (several definitions), Systemic-heuristic, Operational, Sociological, Ecological-economic, Social-ecological, Metaphorical, and Sustainabilty-related. The differences are non- 
trivial, as they include 10 different definitions of the system's postresilience state.

\section{IMPROVING AND BALANCING SQS}

The Technical Briefing will continue by summarizing the major previous contributions to improving and balancing the SQs, represented by references $[1,2 ; 5-9]$. It will then present recent US work in developing ontologies identifying the relations among and sources of variation in quantitative SQ values [3,4,11], and in coordinating these with counterpart efforts in Europe [10] and elsewhere.

The System Qualities Ontology, Tradespace, and Affordability (SQOTA) ontology presented in [3] and updated in [4] is based on the IDEF5 ontology framework, with the top-2 levels of a a classhierarchy SQ framework shown in the table below, and meansends relationships among the SQs. Unlike ISO/IEC 25010, which imposes a strict but unrealistic one-to-many SQ hierarchy, the SQOTA framework permits many-to many relations at level 2 (as with Maintainability) and at lower levels. For example, Testability is a means of achieving many of the level-2 SQs, while it only supports Maintainability in 25010.

\begin{tabular}{|l|l|}
\hline $\begin{array}{l}\text { Stakeholder } \begin{array}{l}\text { Value-Based SQ } \\
\text { Ends }\end{array} \\
\begin{array}{l}\text { Mission } \\
\text { Effectiveness }\end{array}\end{array}$ & $\begin{array}{l}\text { Stakeholders-satisfactory balance of Physical } \\
\text { Capability, Cyber Capability, Human } \\
\text { Usability, Speed, Endurability, } \\
\text { Maneuverability, Accuracy, Impact, } \\
\text { Scalability, Versatility, Interoperability, } \\
\text { Domain-Specific Objectives }\end{array}$ \\
\hline $\begin{array}{l}1.1 \text { Life Cycle } \\
\text { Efficiency }\end{array}$ & $\begin{array}{l}\text { Development and Maintenance Cost, } \\
\text { Duration, Key Personnel, Other Scarce } \\
\text { Resources; Manufacturability, Sustainability }\end{array}$ \\
\hline Dependability & $\begin{array}{l}\text { Reliability, Maintainability, Availability, } \\
\text { Survivability, Robustness, Graceful } \\
\text { Degradation, Security, Safety }\end{array}$ \\
\hline 1.2 Changeability & $\begin{array}{l}\text { Maintainability, Modifiability, Repairability, } \\
\text { Adaptability }\end{array}$ \\
\hline Composite SQs & \\
\hline Affordability & Mission Effectiveness, Life Cycle Efficiency \\
\hline Resilience & Dependability, Changeability \\
\hline
\end{tabular}

The ontology also includes the major sources of SQ value variation in terms of SQ Referents summarizing variations in stakeholder SQ value propositions (e.g., for Dependability, what are the stakeholders depending-on in terms of Mission Effectiveness (speed, accuracy, interoperability, usability, etc.), and in terms of Life-Cycle Efficiency, Dependability, and Changeability, and their various subclasses such as Testability). The other sources of value variation in the ontology are the internal and external system States, internal and external Processes, and synergy and conflict Relations among Dependability and the other SQs. Examples will summarize work to date in identifying synergies and conflicts across the major SQ value categories, and in providing sample quantitative tradespace relationships available for balancing key SQs such as cost, schedule, reliability, and functionality in terms of software size. The briefing will discuss other related research in the area, and the nature of an international collaborative effort to help improve current practices via a Qualipedia for accessing the evolving body of knowledge for improving SQ engineering.
As an example, Reliability is often specified by a one-size-fits-all statement such as, "The system shall have a Mean Time Between Failures (MTBF) of 10,000 hours." In terms of Referents, some stakeholders relying on Liveness may be satisfied by this definition, but other stakeholders needing reliable message delivery may be unsatisfied if the live system delivers several garbled messages per hour.

In terms of States, a system may be declared as Reliable at its Acceptance Test state, but may require further fixes of untested-for failures to be declared Reliable with respect to its Operational state. In terms of Processes, it may provide Reliable message delivery on normal-workload days, but fail often on heavy-workload days. In terms of Relations among the SQs, a system over-optimized for Reliability may fail in terms of Security by having too many redundant points of vulnerability, in terms of Speed in having too many internal checks, and in terms of project Cost and Duration in overdoing Reliability verification and validation.

Thus, the ontology elements enable better support in improving and balancing system qualities. The briefing will also provide quantitative real-project examples.

\section{ACKNOWLEDGMENTS}

This material is based upon work supported in part by the U.S. Department of Defense through the Systems Engineering Research Center (SERC) under Contract H98230-08-D-0171. SERC is a federally funded University Affiliated Research Center managed by Stevens Institute of Technology. It is also supported by the National Science Foundation grant CMMI-1408909, Developing a Constructive Logic-Based Theory of Value-Based Systems Engineering.

\section{REFERENCES}

[1] Barbacci, M., Klein, M., Longstaff, T., and Weinstock, C. 1995. Quality Attributes, Technical Report CMU/SEI-95-TR-1.

[2] Boehm, B., Brown, J., Kaspar, H., Lipow, M., MacLeod, G., and Merritt, M. 1973. Characteristics of Software Quality, NBS Technical Report; 1978. Amsterdam: North Holland.

[3] Boehm, B., and Kukreja, N. 2015. An Initial Ontology for System Quality Attributes. Proceedings, INCOSE IS.

[4] Boehm, B., Chen, C., Shi, L., and Srisopha, K. 2016. The Key Roles of Maintainability in an Ontology for System Qualities. Proceedings, INCOSE IS.

[5] Chung, L., Nixon, B., Yu, E., and Mylopoulos, J. 1999. NonFunctional Requirements in Software Engineering, Kluwer.

[6] Gilb, T. 1988. Principles of Software Engineering Management, Reading MA: Addison-Wesley..

[7] ISO/IEC 2011. Systems and software engineering - SQuaRE system and software quality models standard 25010, ISO/IEC.

[8] Kitchenham, B., and Pickard, L. 1989. Towards a Constructive Software Quality Model. Software Engineering Journal 2(4), 119126.

[9] McCall, J., Richards, P., and Walters, G. 1977. Factors in Software Quality. Rome Air Development Center Report RADC-TR-77-369.

[10] Oriol, M., Marco, J., and Franch, X. 2014. Quality Models for Web Services: A Systematic Mapping, Information and Software Technology 56, 1167-1182.

[11] Ross, A., and Rhodes, D. 2015. Towards a Prescriptive Semantic Basis for Change-Type Ilities, Proc. Conference on Systems Engineering Research 